ISSN: 2146-3042

DOI: $10.25095 /$ mufad.606004

\title{
Modern Portföy Teorisi Işığında Gerçekleşen Getirilerin Beklenen Getirileri Temsil Gücü *
}

\author{
Devran DENIZ** \\ Hasan Aydin OKUYAN ${ }^{* * *}$ \\ Şakir SAKARYA****
}

\section{ÖZET}

Ampirik çalışmalarda genellikle tarihi/gerçekleşen/geçmiş getiriler (ex post/realized return) beklenen/gelecek getirilerin (expected/ex ante return) tahmincisi olarak kullanilmaktadır. Ancak beklenen getirilerin tahmincisi olarak gerçekleșen getirilerin kullanılması durumunda çoğu zaman teorik finansal modellerin beklenen ampirik sonuçları üretmediği görülmektedir. Örneğin modern portföy teorisi teknikleri ile üretilen portföyler geleneksel portföy yönetim teknikleri ile üretilen portföylere göre daha üstün sonuçlar üretmemektedir. Bu sebeple bu çalışmada gerçekleşen getirinin beklenen getirinin iyi bir tahmincisi olup olmadı̆g araşstırlmuştır. Bunun için BiST30'da bulunan hisse senetlerinin geçmiş 1,3 ve 5 ylllk ayllk ortalama getirileri ile gelecek bir yllki ayllk ortalama getirileri ilișkilendirilmiștir. Seçilen geçmiş getiri dönemi kusaldıkça ( 1 ve 3 yll için) gerçekleşen ve gelecek getiri arasinda negatif yönlü ilişski bulunmuştur (mean reversion). Bu sonuca paralel olarak gerçekleșen getirisi düşük şirketlerin gelecek getirisinin diğer şirketlere göre daha yüksek; gerçekleşen getirisi yüksek şirketlerin gelecek getirisinin diğer şirketlere göre daha düşük olduğu görülmüştür. 5 yılllk geçmiş getiri dönemi için ise gerçekleşen ve gelecek getiri arasında pozitif ancak sıfira oldukça yakın bir iliş̧ki (ilişkisizlik) bulunmuştur. Sonuç olarak 5 ylla kadar hesaplanan gerçekleşen getirilerle gelecek getiri arasında pozitif yönlü bir iliş̧ki bulunamamıştır. Bu ise tarihi getirilerin beklenen getirinin iyi bir tahmincisi olmadığına işaret etmektedir. Bu sonuçlar MPT ve CAPM gibi finansal modellerin ampirik testlerinde beklenen getirilerin temsilcisi olarak gerçekleșen getirilerden farklı bir temsilcinin kullanılması gereğine işaret etmektedir.

Anahtar Kelimeler: Tarihi Getiri, Gerçekleşen Getiri, Beklenen Getiri, Gelecek Getiri, Modern Portföy Teorisi.

JEL Sinıflandirması: G10, G17.

\section{The Proxy Power of Realized Return for Expected Return in the Modern Portfolio} Theory Concept

\section{ABSTRACT}

In the empirical studies, realized (ex post) return are generally used as a estimator/proxy of expected return. However, the theoretical financial models do not produce the expected empirical results in the case of using realized return as an estimator of expected return. For example, portfolios produced with modern portfolio theory techniques do not produce superior results compared to portfolios produced with traditional portfolio management techniques. Therefore,in this study it has been investigated whether the realized return is a good estimator of expected return. For this purpose, we have investigated the relationship between the average monthly realized return for 1,3 and 5 years and the monthly average return for the next 1 year. As the selected ex post return period shortened (for 1 and 3 years), it was found that negative correlation between the realized and ex ante return (mean reverse property). Similarly, it has been saw that companies with low realized return have a high ex ante return and the the companies with high realized return have a low ex ante return. For the 5-year period of ex post return, a relationship, which is positive but very close to zero (unrelatedness), was found between the realized return and ex ante return. In summary, there was no positive correlation between the realized return of 1,3 and 5 years and the ex ante return.This suggests that historical returns are not a good estimator of expected return. These results indicate that alternative proxies for expected return must have used in empirical studies about MPT, CAPM etc.

Keywords: Ex Post Return, Realized Return, Expected Return, Ex Ante Return, Modern Portfolio Theory

Jel Classification: G10, G17.

Makale Gönderim Tarihi: 01.06.2019

Makale Kabul Tarihi: 01.08.2019

Makale Türü: Araştırma Makalesi

\footnotetext{
* Bu çalı̧̧ma, 1-4 Mayıs 2019 tarihlerinde Bursa'da düzenlenen V. Uluslararası Muhasebe ve Finans Sempozyumu'nda özet bildiri olarak sunulmuştur.

** Researce Assist., Bandırma Onyedi Eylül Üniversitesi, İIBF İşletme Bölümü, ddeniz@bandirma.edu.tr, ORCID ID: 0000-0003-3808-1929.

*** Associate Prof., Bandırma Onyedi Eylül Üniversitesi, İİBF İşletme Bölümü, hokuyan@bandirma.edu.tr: ORCID ID: 0000-0001-8960-8175.

**** Prof. , Balıkesir Üniversitesi, İIBF İşletme Bölümü, sakarya@balikesir.edu.tr, ORCID ID: 0000-0003-25107384.
} 


\section{GIRIŞ VE LITERATÜR}

Finans literatüründe gerçekleşen veriler (realized/ex post data) genellikle beklenen/gelecek (expected/ex ante) verilerin tahmincisi/temsilcisi (estimator/proxy) olarak kullanılmaktadır. Örneğin modern portföy yönetim tekniklerinde (MPT) gerçekleşen getiriler beklenen getirilerin, gerçekleşen riskler beklenen risklerin, gerçekleşen kovaryanslar da beklenen kovaryansların tahmincisi olarak kullanılmaktadır (Karan, 2011: 145). Benzer şekilde sermaye varlıkları fiyatlama modelinin (SVFM) ampirik testlerinde gerçekleşen getiriler beklenen getirilerin tahmincisi olarak kullanılmaktadır. Buradaki temel hipotez gerçekleşen getirilerin beklenen getirilerin yansız tahmincisi olduğu düşüncesidir (Elton, 1999: 1199). Ancak gerçekleşen getirilerin beklenen getirilerin iyi bir tahmincisi olup olmadığına dair kuşkular bulunmaktadır.

Örneğin gelişmiş ülke piyasalarından ABD piyasasında hisse senedi piyasasının risksiz faiz oranından daha düşük getiri sağladığı 11 yıllık süre (1973-1984) ve uzun dönemli tahvil getirilerinin risksiz faiz oranından daha düşük getiri sağladığı 50 yıldan daha uzun bir dönem (1927-1981) bulunmaktadır (Elton, 1199). Söz konusu dönemler oldukça uzun olup gerçekleşen getirileri gelecekteki beklentilerin en iyi tahmincisi olarak kullanmanın ne kadar hatalı olabileceğini göstermektedir.

Nitekim söz konusu kullanım nedeni ile çeşitli finans teorileri için ampirik çalışma yapan araştırmacılar teorilerin desteklediğinden çok farklı sonuçlar elde etmiştir. Örneğin beklenen getiriler için tarihi getirileri kullanan modern portföy yönetimi tekniklerinin ampirik sonuçlarının geleneksel portföy yönetimi tekniklerine göre daha üstün sonuçlar üretmediğine dair çok sayıda çalışma vardır. Örneğin Demiguel vd. (2007) yaptıkları çalışmada ortalama varyans modeli ve onun uzantılarını içeren (Bayesien yaklaşım, Kan ve Zhou's "three fund" modeli gibi) 14 farklı modelle 7 farklı dönem için portföyler oluşturmuş ve bu modellerin hiçbirinin gerçekleşen performansları bakımından $1 / \mathrm{N}$ çeşitlendirmesine sürekli olarak üstün gelmediğini ortaya koymuştur. Benzer şekilde Mora ve diğ. (2010) yaptıkları çalışmada 4 farklı modelle (varyans- kovaryans matrisi; yarı varyans kovaryans matrisi, üssel hareketli ortalamalar, resampling) oluşturdukları portföylerin eşit ağırlıklı portföye göre daha yüksek performans (sharpe rasyosu) üretmediklerini tespit etmiştir. Berg (2005) ortalama varyans optimizasyon tekniğinin 6 aylık süre için hesapladığ 1 gerçekleşen portföy performansını artırmadığını tespit etmiştir. Deniz ve Okuyan (2018) Borsa İstanbul'da ortalama varyans modeli ve yalın çeşitlendirme $(1 / \mathrm{N})$ ile portföyler oluşturmuş ve portföylerin ampirik sonuçlarını karşılaştırmıştır. Bunun için Borsa İstanbul'da hisse senetleri beşerli toplam 46 gruba ayrılmış ve her bir grup için her iki yöntemle portföyler oluşturulmuştur. Oluşturulan portföyler farklı dönemler için çok sayıda tekrarlanmış ve birbirleri ile karşılaştırılmıştır. Sonuçta ortalama varyans modeli ile üretilen portföylerin yalın çeşitlendirme ile üretilen portföylere üstün gelmediği görülmüştür. Tang (2004) ise eşit ağırlıklı bir çeşitlendirme ile 20 hisse senedinden oluşan portföyün sistematik olmayan riskin ortalama \%95'inin elimine edilebileceğini tespit etmiştir. Yani elde edilen sonuçlar genellikle modern portföy tekniklerinin ürettiği portföylerin daha düşük performans gösterdiği yönündedir. Benzer şekilde sermaye varlıkları fiyatlama modeline dair yapılan ampirik çalışmaların da beklenenden farklı sonuçlar üretebildiği görülmektedir (Horimoto ve Tareq, 2013: 743). 
$\mathrm{Bu}$ nedenlerle gerçekleşen getirilerin beklenen getirilerin bir gerçekleşmesi olup olmadığı araştırılmalı ve söz konusu hipotez doğrulanamazsa ortalama gerçekleşen getiri beklenen getirinin tahmincisi olarak kullanılmamalıdır (Horimoto ve Tareq, 2013: 743).

Elton (1999) yaptığı çalışmada piyasada bilgi sürprizlerinin “information surprises” varlığı nedeniyle tarihi getirilerin beklenen getirilerin iyi bir tahmincisi olmadığını tespit etmiştir. Brav vd. (2001) beklenen getiriler için gerçekleşen getiriler yerine yatırım analisti beklentilerini kullandığında sermaye varlıkları fiyatlama modeline uygun olan ampirik sonuçlar elde etmiştir. Örneğin beta ile beklenen getiriler arasında aynı yönlü ilişkiler elde etmiştir. Ayrıca şirketlerin beklenen getirisi ile cari fiyatı arasında negatif ilişki olduğu, küçük şirketlerin beklenen getirisinin büyük şirketlere göre daha yüksek olduğu (risk getiri trade off kuralı ile uyumlu) sonuçlarına ulaşı1mıştır. Gebhardt vd. (2001), Horimoto ve Tareq (2013) bu şekilde düşünen diğer öncü araştırmacılardandır (Horomoto ve Tareq, 2013: 744).

Özet olarak literatürde gerçekleşen getirinin beklenen getirinin iyi bir tahmincisi olmamasının birinci sebebi olarak gerçekleşen getirideki gürültünün "noise" yüksek olması, ikinci sebebi olarak ise gelecekteki bir zaman periyodunda bilgi sürprizlerinin etkisinin dengelenmemesi yani sıfırlanmaması olarak görülmektedir (Brav vd., 2014: 3).

Dolayısıyla gerçekleşen getirilerin beklenen getirinin ne kadar iyi bir tahmincisi olduğuna dair yapılacak çalışmalar önem kazanmaktadır. Hatta bu sonuçların ışı̆̆ında Elton'un da (1999) ifade ettiği gibi geçmiş verileri tahminci olarak kullanmayan yeni tekniklerin geliştirilmesi önemli görülmektedir. Bu çalışmada BİST30 özelinde geçmiş getirilerin gelecek getirilerin ne kadar iyi bir tahmincisi olduğunun ampirik testi araştırılmıştır. Araştırmalardan görüldügü kadarıyla, bu alanda hem Borsa İstanbul özelinde bu alanda yapılacak ilk çalışma hem de ilk Türkçe eser olması bakımından literatüre katkı sağlayacağı düşünülmektedir.

\section{DATA VE METODOLOJI}

Gerçekleşen getirilerin beklenen getirinin iyi bir tahmincisi olup olmadığının anlaşılması için gerçekleşen getirilerle (realized return) gelecek getiriler (ex ante return) ilişkilendirilmiştir. Bunun için bir, üç ve beş yıllık gerçekleşen aylık ortalama getiriler ile bir yıllık gelecek (ex ante) aylık ortalama getiriler ilişkilendirilmiştir. Eğer pozitif yönlü bir ilişki varsa bu ilişki gelecek getirilerin gerçekleşen getiriler ile temsil edilen beklenen getirinin bir gerçekleşmesi olduğu anlamına gelir. Tersi durumda yani geçekleşen ve gelecek getiriler arasında ilişki bulunmaması durumunda ise gerçekleşen getirinin beklenen getirinin iyi bir tahmincisi olmadı̆̆ anlaşılır.

Gerçekleşen getiriler geçmiş bir, üç ve beş yıllık aylık ortalama getiri şeklinde hesaplanmıştır. Gelecek getiriler ise gelecek 1 yılki aylık ortalama getiri şeklinde hesaplanmıştır. ${ }^{1}$

t: tahmin yapılan zaman noktasını (her bir yılda her bir ayın sonu),

\footnotetext{
${ }^{1}$ Standart olmamakla birlikte aylık veriler kullanıldığında genellikle gerçekleşen 3 veya 5 yıllık veri dönemine bakılarak beklenen getiriler tahmin edilmeye çalışılır. Gelecek getirilerin ise sadece bir aylık yerine bir yıl olarak alınmasının nedeni ise mevsimsellik gibi faktörlerin etkilerinin giderilmesi isteğidir.
} 
RR1= Average $\left(\mathrm{R}_{\mathrm{t}-12, \mathrm{t}}\right)$ : Geçmiş 1 y1l (12 ay) için aylık ortalama gerçekleşen getiri (realized return)

$\mathrm{RR} 3=$ Average $\left(\mathrm{R}_{\mathrm{t}-36, \mathrm{t}}\right)$ : Geçmiş 3 y1l (36 ay) için aylık ortalama gerçekleşen getiri (realized return)

$\mathrm{RR} 5=$ Average $\left(\mathrm{R}_{\mathrm{t}-60, \mathrm{t}}\right)$ : Geçmiş 5 y1l (60 ay) için aylık ortalama gerçekleşen getiri (realized return) (ex ante)

EA1= Average $\left(\mathrm{R}_{\mathrm{t}, \mathrm{t}+12}\right)$ : Gelecek 1 y1l (12) için aylık ortalama tahmin edilen getiriyi

göstermek üzere çalışmanın alternatif hipotezi:

$\mathrm{H}_{\mathrm{A}}$ : Gerçekleşen getiriler ile (RR1, RR3, RR5) gelecek getiriler (EA1) arasında pozitif yönlü lineer bir ilişki vardır.

Söz konusu ilişki Stata 13.0 paket programında her bir şirket için lineer regresyon analizi ile test edilmiştir. Ayrıca her bir şirket için RR1/3/5 ile EA1 arasındaki pearson korelasyon katsayısının işareti ve anlamlı olup olmadığı da araştırılarak değişkenler arasındaki ilişkinin gücü standart olarak ölçülmüsşür. Son olarak değişkenler kategorilere ayırılarak gerçekleşen getirilerin gelecek getirilerin bir tahmincisi olup olmadığı daha yalın bir şekilde görülmeye çalışılmıştır.

Çalışmanın ana kütlesi Borsa İstanbul'a kote olan şirketler ve örnek kütlesi BIST30 endeksindeki şirketlerdir. Veri dönemi ise 2005-2018 yılları arası olarak alınmıştır. Bu durumda RR1 ile EA1 arasındaki ilişki 2005 yılı Aralık ayı sonundan, 2017 yılı Aralık ayı sonuna kadar ölçülmüştür. Çünkü 1 yıllık gerçekleşen getiriyi (RR1) elde edebilmek için 12 aylık geçmiş getiriye ihtiyaç vardır. Bu nedenle gerçekleşen getirinin ilk elde edildiği zaman 2005 yılı aralık ayının sonu olmuştur. Dolayısıyla Söz konusu 2005 yılı için elde edilen 12 aylık ortalama gerçekleşen getiri ile 2006 yılı aylık ortalama getirisi ilişkilendirilmiştir. Bu şekilde devam edilerek en son 2017 yılı Aralık ayında son 12 aylık gerçekleşen getiri ile 2018 yılındaki gelecek getiri ilişkilendirilmiştir. Bu tarihten sonra 1 y1llık gelecek getiri söz konusu değildir. Dolayısıyla sadece bir şirket için 144 gözlem (12 y1 ${ }^{*} 12$ ay) elde edilmiştir. RR3 ile EA1 arasında ise her bir şirket için 120 gözlem $\left(10^{*} 12\right)$, son olarak RR5 ile EA1 arasında ise 96 gözlem $(8 * 12)$ elde edilmiştir.

BİST30 endeksine ait şirketlerden 2005 yılına kadar aylık pay senedi fiyat bilgisi mevcut olan 20 şirket ile hipotez testleri gerçekleştirilmiştir. Tablo 1'de söz konusu 20 şirket bilgisi görülmektedir. Şirketlerin pay senedi fiyatları nakit temettü ve pay senedi sayısındaki değişimlere göre geçmişe göre düzeltilmiş fiyatlar alınarak kullanılmıştır. Söz konusu bilgiler Finnet Hisse Expert programından temin edilmiştir. 
Tablo 1. Analize Dâhil Edilen BİST30 Şirketleri

\begin{tabular}{|c|c|c|c|}
\hline & Şirket Kodu & Şirket Adı & Sektör \\
\hline 1 & AKBNK & Akbank T.A.Ş & Mali Kuruluş \\
\hline 2 & ARCLK & Arçelik A.Ş & Teknoloji \\
\hline 3 & ASELS & Aselsan Elektronik Sanayi ve Ticaret A.Ş & Mali Kuruluş \\
\hline 4 & DOHOL & Doğan Şirketler Grubu A.Ş & İmalat Sanayi \\
\hline 5 & EREGL & Ereğli Demir ve Çelik Fabrikaları A.Ş & İmalat Sanayi \\
\hline 6 & FROTO & Ford Otomotiv Sanayi A.Ş & Mali Kuruluş \\
\hline 7 & GARAN & Türkiye Garanti Bankası A.Ş & Mali Kuruluş \\
\hline 8 & ISCTR & Türkiye İş Bankası A.Ş & İmalat Sanayi \\
\hline 9 & KRDMD & Kardemir Karabük Demir Çelik San. ve Tic. A.Ş & Mali Kuruluş \\
\hline 10 & KCHOL & Koç Holding A.Ş. & Madencilik \\
\hline 11 & KOZAA & Koza Anadolu Metal Madencilik işletmeleri A.Ş & İalat Sanayi \\
\hline 12 & PETKM & Petkim Petrokimya Holding A.Ş. & İmalat Sanayi \\
\hline 13 & SAHOL & Hacı Ömer Sabancı Holding A.Ş. & İmalat Sanayi \\
\hline 14 & SODA & Soda Sanayi A.Ş. & İmalat Sanayi \\
\hline 15 & SISE & Türkiye Şişe ve Cam Fabrikaları A.Ş. & Ulaştırma, Haberleşme \\
\hline 16 & TOASO & Tofaş Türk Otomobil Fabrikası A.Ş. & İmalat Sanayi \\
\hline 17 & TCELL & Türkcell İletişim Hizmetleri A.Ş. & Ulaştırma, Haberleşme \\
\hline 18 & TUPRS & Tüpraş Türkiye Petrol Rafineleri A.Ş. & Mali Kuruluş \\
\hline 19 & THYAO & Türk Hava Yolları Anonim Ortaklığ1 & \\
\hline 20 & YKBNK & Yapı ve Kredi Bankası A.Ş. & \\
\hline
\end{tabular}

Tablo 1'deki 20 şirketin 9'u imalat sanayi, 7'si mali kuruluş, 2'si ulaştırma ve haberleşme 1'i teknoloji, 1'i de madencilik sektörlerine aittir.

\section{BULGULAR}

Öncelikle 1 yıllık gerçekleşen getirilerin beklenen getiriyi temsil gücü incelenmiş bunun için RR1 (realized return) ile EA1 (ex ante return) arasındaki lineer regresyon ve pearson korelasyon katsayısı her bir şirket için hesaplanarak aşağıda sunulmuştur. 
Tablo 2. Gerçekleşen (1 yıllık) ve Gelecek Getiriler Arasındaki İlişki

\begin{tabular}{|l|c|c|c|c|}
\hline \multicolumn{5}{|c|}{ EA1 $=\alpha+\beta *$ RR1 } \\
\hline Şirket & $\begin{array}{c}\text { Gözlem } \\
\text { Say1s1 }\end{array}$ & $\begin{array}{c}\text { Regresyon } \\
\text { katsay1s1 }(\beta)\end{array}$ & Sign. & $\begin{array}{c}\text { Korelasyon } \\
\text { katsay1s1 }(\rho)\end{array}$ \\
\hline AKBNK & 144 & $\mathbf{- 0 , 4 2}$ & 0,00 & $\mathbf{- 0 , 4 3}$ \\
\hline ARCLK & 144 & $\mathbf{- 0 , 1 9}$ & 0,03 & $\mathbf{- 0 , 1 8}$ \\
\hline ASELS & 144 & $\mathbf{- 0 , 2 3}$ & 0,01 & $\mathbf{- 0 , 2 3}$ \\
\hline DOHOL & 144 & $\mathbf{- 0 , 2 3}$ & 0,00 & $\mathbf{- 0 , 2 4}$ \\
\hline EREGL & 144 & $\mathbf{- 0 , 2 3}$ & 0,01 & $\mathbf{- 0 , 2 3}$ \\
\hline FROTO & 144 & $\mathbf{- 0 , 2 9}$ & 0,00 & $\mathbf{- 0 , 2 9}$ \\
\hline GARAN & 144 & $\mathbf{- 0 , 5 3}$ & 0,00 & $\mathbf{- 0 , 5 3}$ \\
\hline ISCTR & 144 & $\mathbf{- 0 , 5 5}$ & 0,00 & $\mathbf{- 0 , 5 5}$ \\
\hline KRDMD & 144 & $\mathbf{- 0 , 5 0}$ & 0,00 & $\mathbf{- 0 , 4 5}$ \\
\hline KCHOL & 144 & $\mathbf{- 0 , 3 7}$ & 0,00 & $\mathbf{- 0 , 3 7}$ \\
\hline KOZAA & 144 & $-0,11$ & 0,16 & $-0,12$ \\
\hline PETKM & 144 & $\mathbf{- 0 , 3 9}$ & 0,00 & $\mathbf{- 0 , 3 8}$ \\
\hline SAHOL & 144 & $\mathbf{- 0 , 3 6}$ & 0,00 & $\mathbf{- 0 , 3 7}$ \\
\hline SODA & 144 & $-0,05$ & 0,50 & $-0,06$ \\
\hline SISE & 144 & $-0,04$ & 0,64 & $-0,04$ \\
\hline TOASO & 144 & $\mathbf{- 0 , 2 5}$ & 0,00 & $\mathbf{- 0 , 2 5}$ \\
\hline TCELL & 144 & $\mathbf{- 0 , 5 2}$ & 0,00 & $\mathbf{- 0 , 5 1}$ \\
\hline TUPRS & 144 & $\mathbf{- 0 , 4 4}$ & 0,00 & $\mathbf{- 0 , 4 5}$ \\
\hline THYAO & 144 & $\mathbf{- 0 , 3 6}$ & 0,00 & $\mathbf{- 0 , 3 5}$ \\
\hline YKBNK & 144 & $\mathbf{- 0 , 5 0}$ & 0,00 & $\mathbf{- 0 , 4 8}$ \\
\hline TOTAL & $\mathbf{2 . 8 8 0}$ & $\mathbf{- 0 , 2 4}$ & 0,00 & $\mathbf{- 0 , 2 4}$ \\
\hline
\end{tabular}

En küçük kareler varsayımları sağlanmıştır. ${ }^{2}$

Tablo 2'den görülmektedir ki her bir şirket için tahmin edilen regresyon katsayısı negatif ve 3 şirket hariç hepsi istatistiksel açıdan anlamlıdır. Korelasyon katsayıları da regresyon katsayıları gibi negatif ve anlamlıdır. Bütün şirketlerin toplam 2.880 gözlemi için regresyon katsayısı ve korelasyon katsayısı -0,24 ve istatistiksel açıdan anlamlı bulunmuştur. Yani gerçekleşen getirilerle gelecek getiriler arasında negatif yönlü ve istatistiksel açıdan anlamlı bir ilişski vardır $\left(\mathrm{H}_{\mathrm{A}}\right.$ hipotezi reddedilmiştir). $\mathrm{Bu}$ ise 1 yıllık gerçekleşen getirilerin gelecek getirilerin iyi bir tahmincisi olmadığına işaret etmektedir.

Gerçekleşen getirinin beklenen getirinin bir tahmincisi olarak kullanılamayacağının daha net şekilde görülebilmesi için kategorik analiz yapılmış ve sonuçlar Tablo 3'te sunulmuştur. Bunun için gerçekleşen getirilere göre gözlemler 4 kategoriye (gruba) ayrılmıştır. Daha sonra her bir kategorideki şirket gözleminin gelecek getirileri ölçülmüş̧ür. Eğer gerçekleşen getiriler gelecek getirilerin iyi bir tahmincisi ise geçmişte düşük/yüksek getiri sağlayan şirketlerin gelecekte de düşük/yüksek getiri sağlaması gerekmektedir. Tablo 4 Panel A'da grup içi karş1laştırmalar bulunmaktadır. Gerçekleşen getirileri düşük olan şirketlerin gelecek getirilerinin yükseldiği, gerçekleşen getirileri yüksek olan şirketlerin ise

\footnotetext{
${ }^{2}$ Her bir şirket için gözlem sayısının 30’dan büyük olması ve değişkenlerin \%95 seviyesinde winsorize edilmesi nedeniyle değişkenlerin normal dağıldığı kabul edilmiştir. Ayrıca regresyon katsayıları otokorelasyon ve değişen varyansa karşı dirençli White (1980) tahmincisi ile tahmin edilmiştir. Basit doğrusal regresyon olduğu için çoklu doğrusal bağlantı sorunu bulunmamaktadır.
} 
gelecek getirilerinin düştüğü görülmektedir. Örneğin geçmiş 3 yıllık aylık ortalama getirisi $\% 2,7$ olan şirketler sonraki 1 yılda aylık ortalama \%2,7 getiri sağlamışlardır ve iki oran arasındaki fark $(\% 5,4)$ istatistiksel açıdan anlamlıdır. Benzer şekilde 1 yıllık gerçekleşen getirisi en yüksek grupta olan şirketler (\%5,6 aylık ortalama getiri) gelecek 1 yılda aylık ortalama \%0,7 getiri sağlamıştır ve aradaki negatif fark $(-\% 4,9)$ istatistiksel açıdan anlamlıdır. Diğer gruplar için de sonuçlar benzerdir. Yani gerçekleşen getiriler ile gelecek getiriler arasındaki negatif yönlü ilişki görünmektedir. Ayrıca görülmektedir ki gerçekleşen getirisi en düşük veya düşük grupta olan şirketlerin gelecek yılki getirileri (\%2.7 ve \%1.1), diğer iki gruba göre (\%0.6 ve \%0.7) daha yüksektir. Panel B'de grupların gelecek yılki getirileri arasındaki farklılıkların anlamlılık seviyeleri bulunmaktadır. 3 ve 4 numaralı gruplar hariç bütün gruplar arasındaki farklılıklar anlamlıdır. Yani örneğin gerçekleşen getirisi en yüksek olan grubun gerçekleşen getirisi en düşük olan gruba göre gelecek 1 yilki aylık ortalama getirisi $\% 2$ daha düşük olup bu fark \%1 seviyesinde anlamlıdır.

Tablo 3. Gerçekleşen (1 yıllık) ve Gelecek Getiriler Arasındaki Kategorik İlişki

Panel A.

\begin{tabular}{|cl|c|c|c|c|c|}
\hline \multicolumn{1}{|c|}{ Kategori } & $\begin{array}{c}\text { Gözlem } \\
\text { Sayı1 }\end{array}$ & $\begin{array}{c}\text { Gerçekleşen Getiri } \\
\text { Ort. Ayl. (\%) }\end{array}$ & $\begin{array}{c}\text { Gelecek Getiri Ort. } \\
\text { Ayl. (\%) }\end{array}$ & Fark & Sign. \\
\hline 1. & Grup (En düşük gerç. Get.) & 720 & $-2,7$ & 2,7 & 5,4 & 0,00 \\
\hline 2. & Grup (Düşük gerç. Get.) & 720 & 0,5 & 1,1 & 0,6 & 0,01 \\
\hline 3. & Grup (Yüksek ger. Get.) & 720 & 2,3 & 0,6 & $-1,7$ & 0,00 \\
\hline 4. & Grup (En yüksek ger. Get.) & 720 & 5,6 & 0,7 & $-4,9$ & 0,00 \\
\hline
\end{tabular}

Ortalamalar arasındaki farkların anlamlı olup olmadığı konusunda eşleştirilmiş örneklem t testi kullanılmıştır. Çünkü her bir gözlemin (şirketin) gerçekleşen ve gelecek getirileri karşılaştırıldığ için paired sample $t$ testi tercih edilmiştir.

Panel B (One way Anowa Tukey Testi Sonuçları)

\begin{tabular}{|c|c|c|c|c|}
\hline $7_{(\mathrm{I})}^{(\mathrm{J})}$ & $\begin{array}{l}\text { 1. En Düşük } \\
\text { Gerç. Get. } \\
\text { Grubu }\end{array}$ & $\begin{array}{l}\text { 2. Düşük } \\
\text { Gerç. Get. } \\
\text { Grubu }\end{array}$ & $\begin{array}{l}\text { 3. Yüksek } \\
\text { Gerç. Get. } \\
\text { Grubu }\end{array}$ & $\begin{array}{l}\text { 4. Grup (En } \\
\text { yüksek ger. } \\
\text { Get.) }\end{array}$ \\
\hline 1. En Düşük Gerç. Get. Grubu & . & & & \\
\hline 2. Düşük Gerç. Get. Grubu & $\begin{array}{c}\mathbf{- 1 , 6 \%} \\
0,001\end{array}$ & . & & \\
\hline 3. Yüksek Gerç. Get. Grubu & $\begin{array}{c}-2,1 \% \\
0,001\end{array}$ & $\begin{array}{c}\mathbf{- 0 , 5 \%} \\
0,03\end{array}$ & - & \\
\hline 4. Grup (En yüksek ger. Get.) & $\begin{array}{c}-2,0 \% \\
0,001\end{array}$ & $\begin{array}{c}\mathbf{- 0 , 4 \%} \\
0,05\end{array}$ & $\begin{array}{c}0,1 \% \\
0,82\end{array}$ & . \\
\hline
\end{tabular}

Tabloda her bir grubun gelecek getirileri arasındaki fark (I-J) ve anlamlılık seviyesi bulunmaktadır.

Regresyon analizi sonucunda elde edilen geçmiş getirilerle gelecek getiriler arasındaki negatif yönlü ilişki literatürde ortalamaya dönüş (mean reversion) olarak ifade edilmekte ve ampirik araştırmalar tarafindan desteklenmektedir (Chaudhuri ve $\mathrm{Wu}, 2003$ : 22). Kim vd. (1991), Balvers, Wu ve Gilliland (2002), Chaudhuri ve Wu (2003), Bali vd. (2008) ve Mukherji (2011) bu yönde bulgular elde eden araştırmacılardır. Ancak kategorik analiz sonuçları söz konusun negatif yönlü ilişkinin ne kadar önemli olduğunu göstermektedir. Nitekim 1 yıllık gerçekleşen getirisi en düşük veya düşük seviyede olan şirketlerin ertesi yıl getirisi diğerlerine göre oldukça yüksektir. Bu nedenle 1 yıllık gerçekleşen getirinin beklenen getirinin iyi bir tahmincisi olmadığ ne kadar hatalı sonuçlara sebep olabileceği görülmektedir. 
Gerçekleşen getiri olarak geçmiş 3 yil alınarak elde edilen sonuçlar ise Tablo 4'te sunulmuştur. Elde edilen sonuçlar geçmiş 1 yıllık getirilerin kullanılmasıyla elde edilen sonuçlara benzerdir. Görüldüğü gibi 20 şirket için gerçekleşen ve gelecek getiriler arasında negatif regresyon ve korelasyon katsayısı elde edilmiş ve 1 şirket hariç hepsi istatistiksel açıdan anlamlı bulunmuştur. Toplam 2 bin 400 gözlem için regresyon ve korelasyon katsayılarını sırasıyla $-0,50$ ve $-0,23$ ’tür.

Tablo 4. Gerçekleşen (3 y1llık) ve Gelecek Getiriler Arasındaki İlişki

\begin{tabular}{|l|c|c|l|c|}
\hline \multicolumn{5}{|c|}{ EA1 $=\alpha+\beta *$ RR3 } \\
\hline Sirket & $\begin{array}{c}\text { Gözlem } \\
\text { Say1s1 }\end{array}$ & $\begin{array}{c}\text { Regresyon } \\
\text { katsay1S1 }(\beta)\end{array}$ & Sign. & $\begin{array}{c}\text { Korelasyon } \\
\text { katsay1s1 }(\rho)\end{array}$ \\
\hline AKBNK & 120 & $\mathbf{- 1 , 3 2}$ & 0,00 & $\mathbf{- 0 , 4 4}$ \\
\hline ARCLK & 120 & $\mathbf{- 0 , 7 8}$ & 0,00 & $\mathbf{- 0 , 3 8}$ \\
\hline ASELS & 120 & $\mathbf{- 0 , 7 8}$ & 0,00 & $\mathbf{- 0 , 3 9}$ \\
\hline DOHOL & 120 & $\mathbf{- 0 , 7 7}$ & 0,00 & $\mathbf{- 0 , 3 9}$ \\
\hline EREGL & 120 & $\mathbf{- 1 , 4 3}$ & 0,00 & $\mathbf{0 , 4 6}$ \\
\hline FROTO & 120 & $\mathbf{- 0 , 7 8}$ & 0,00 & $\mathbf{- 0 , 3 7}$ \\
\hline GARAN & 120 & $\mathbf{- 0 , 9 4}$ & 0,00 & $\mathbf{- 0 , 3 3}$ \\
\hline ISCTR & 120 & $\mathbf{- 1 , 6 9}$ & 0,00 & $\mathbf{- 0 , 5 5}$ \\
\hline KRDMD & 120 & $\mathbf{- 0 , 9 0}$ & 0,00 & $\mathbf{- 0 , 2 7}$ \\
\hline KCHOL & 120 & $\mathbf{- 1 , 4 2}$ & 0,00 & $\mathbf{- 0 , 4 5}$ \\
\hline KOZAA & 120 & $\mathbf{- 0 , 8 4}$ & 0,00 & $\mathbf{- 0 , 3 5}$ \\
\hline PETKM & 120 & $\mathbf{- 0 , 8 3}$ & 0,00 & $\mathbf{- 0 , 3 4}$ \\
\hline SAHOL & 120 & $-0,31$ & 0,13 & $-0,14$ \\
\hline SODA & 120 & $\mathbf{- 0 , 9 5}$ & 0,00 & $\mathbf{- 0 , 3 7}$ \\
\hline SISE & 120 & $\mathbf{- 0 , 7 5}$ & 0,00 & $\mathbf{- 0 , 5 0}$ \\
\hline TOASO & 120 & $\mathbf{- 0 , 9 0}$ & 0,00 & $\mathbf{- 0 , 5 2}$ \\
\hline TCELL & 120 & $\mathbf{- 1 , 2 0}$ & 0,00 & $\mathbf{- 0 , 4 7}$ \\
\hline TUPRS & 120 & $\mathbf{- 1 , 2 5}$ & 0,00 & $\mathbf{- 0 , 5 4}$ \\
\hline THYAO & 120 & $\mathbf{- 1 , 5 2}$ & 0,00 & $\mathbf{- 0 , 5 6}$ \\
\hline YKBNK & 120 & $\mathbf{- 1 , 6 6}$ & 0,00 & $\mathbf{- 0 , 5 6}$ \\
\hline TOTAL & $\mathbf{2 4 0 0}$ & $\mathbf{- 0 , 5 0}$ & 0,00 & $\mathbf{- 0 , 2 3}$ \\
\hline
\end{tabular}

En küçük kareler varsayımları sağlanmıştır. ${ }^{3}$

Benzer şekilde Tablo 5'te gerçekleşen (3 yıllık) ve gelecek getiriler arasındaki kategorik ilişki sonuçları sunulmuştur. Sonuçlar Tablo 3'dekine benzerdir. Gerçekleşen getirisi düşük olan şirketlere ait gözlemlerin gelecek yılki getirileri yükselmekte, gerçekleşen getirisi yüksek olanların gelecek getirileri ise düşüş göstermektedir. Ayrıca grupların gelecek getirileri arasındaki farkların anlamlılığı Panel B'de gösterilmiştir. Görüldüğü gibi gerçekleşen getirisi en düşük olan 1. Grubun gelecek yılki ortalama getirisi diğerlerinden anlamlı şekilde büyüktür. Diğer grupların ortalaması arasındaki farklar anlamlı değildir.

Yani gerçekleşen getiri için geçmiş 1 yılın kullanılması durumundaki kadar güçlü olmasa da gerçekleşen ve gelecek getiriler arasındaki negatif yönlü ilişkinin mevcut olduğu

\footnotetext{
${ }^{3}$ Her bir şirket için gözlem sayısının 30'dan büyük olması ve değişkenlerin \%95 seviyesinde winsorize edilmesi nedeniyle değeşkenlerin normal dağıldığı kabul edilmiştir. Ayrıca otokorelasyon ve değişen varyans olması durumunda dahi regresyon katsayısının doğrusal en iyi sapmasız tahminci olma özelliğini koruduğundan dolayı herhangi bir ilave işlem yapılmamıştır. Basit doğrusal regresyon olduğu için çoklu doğrusal bağlantı sorunu bulunmamaktadır.
} 
anlaşılmaktadır. Bu da 3 yıllık gerçekleşen getirinin de beklenen getirinin temsilcisi olarak kullanılmasının hatalı olduğunu göstermektedir.

Tablo 5. Gerçekleşen (3 yıllık) ve Gelecek Getiriler Arasındaki Kategorik İlişki

Panel A

\begin{tabular}{|l|c|c|c|c|c|}
\hline \multicolumn{1}{|c|}{ Kategori } & $\begin{array}{c}\text { Gözlem } \\
\text { Sayıs1 }\end{array}$ & $\begin{array}{c}\text { Gerçekleşen Getiri } \\
\text { Ort. Ayl. (\%) }\end{array}$ & $\begin{array}{c}\text { Gelecek Getiri Ort. } \\
\text { Ayl. (\%) }\end{array}$ & Fark & Sign. \\
\hline 1. $\quad$ Grup (En düşük gerç. Get.) & 484 & $-0,8$ & 3,3 & 4,1 & 0,00 \\
\hline 2. $\quad$ Grup (Düşük gerç. Get.) & 484 & 0,6 & 1,0 & 0,4 & 0,01 \\
\hline 3. $\quad$ Grup (Yüksek ger. Get.) & 484 & 1,7 & 1,1 & $-0,6$ & 0,00 \\
\hline 4. $\quad$ Grup (En yüksek ger. Get.) & 484 & 3,3 & 1,5 & $-1,8$ & 0,00 \\
\hline
\end{tabular}

Ortalamalar arasındaki farkların anlamlı olup olmadığı konusunda eşleştirilmiş örneklem t testi kullanılmıştır. Çünkü her bir gözlemin (şirketin) gerçekleşen ve gelecek getirileri karşılaştırıldığı için paired sample t testi tercih edilmiştir.

Panel B (One way Anowa Tukey Testi Sonuçları)

\begin{tabular}{|c|c|c|c|c|}
\hline $7_{(\mathrm{I})}^{(\mathrm{J})}$ & $\begin{array}{l}\text { 1. En Düşük } \\
\text { Gerç. Get. } \\
\text { Grubu }\end{array}$ & $\begin{array}{l}\text { 2. Düşük } \\
\text { Gerç. Get. } \\
\text { Grubu }\end{array}$ & $\begin{array}{l}\text { 3. Yüksek } \\
\text { Gerç. Get. } \\
\text { Grubu }\end{array}$ & $\begin{array}{l}\text { 4. Grup (En } \\
\text { yüksek ger. } \\
\text { Get.) }\end{array}$ \\
\hline 1. En Düşük Gerç. Get. Grubu & . & & & \\
\hline 2. Düşük Gerç. Get. Grubu & $\begin{array}{c}-2,3 \\
0,001\end{array}$ & $\cdot$ & & \\
\hline 3. Yüksek Gerç. Get. Grubu & $\begin{array}{c}-2,2 \\
0,001\end{array}$ & $\begin{array}{c}0,1 \\
0,83 \\
\end{array}$ & - & \\
\hline 4. Grup (En yüksek ger. Get.) & $\begin{array}{c}\mathbf{- 1 , 8} \\
0,001 \\
\end{array}$ & $\begin{array}{c}0,5 \\
0,11 \\
\end{array}$ & $\begin{array}{c}0,4 \\
0,82 \\
\end{array}$ & \\
\hline
\end{tabular}

Tabloda her bir grubun gelecek getirileri arasındaki fark (I-J) ve anlamlllık seviyesi bulunmaktadır.

Çalışmada son olarak 5 yıllık gerçekleşen getirilerin gelecek bir yıllık getirisi ile ilişkisi aynı yönlü ancak oldukça zayıf olduğu tespit edilmiş olup sonuçlar detaylı olarak gösterilmemiştir. Aralarındaki regresyon katsayısı ve korelasyon katsayısı sırasıyla 0,11 ve 0,04 olup istatistiksel açıdan anlamlıdır. Ancak söz konusu ilişki sıfıra oldukça yakındır.

$\mathrm{Bu}$ sonuçlardan anlaşılmaktadır ki, 5 yıla kadar süreyle hesaplanan gerçekleşen getiriler ile gelecek getiriler arasında pozitif yönlü bir ilişki bulunmamaktadır. Gerçekleşen getirilerin dönemi kısaldıkça negatif yönlü ilişki, gerçekleşen getirinin dönemi uzadıkça ilişkisizlik görülmektedir. $\mathrm{Bu}$ ise 5 yıla kadar süreyle hesaplanan gerçekleşen getirilerin beklenen getirinin tahmincisi olarak kullanılamayacağını göstermektedir. 


\section{SONUÇ}

Birçok finansal çalışmada gerçekleşen getiriler beklenen getirinin tahmincisi olarak kullanılmaktadır. Ancak bu durumda MPT, SVFM gibi finans teorilerinin ampirik sonuçları teoriyle uyumlu olmayabilmektedir. Yapılan araştırmalarda özellikle MPT'nin geleneksel portföy teorisine göre daha üstün performanslı portföyler üretmediği hatta çoğu zaman daha düşük performanslı portföyler oluşturduğu görülmektedir. Elton (1999), Gebhardt vd. (2001) ve Horimoto ve Tareq (2013) gibi bazı araştırmacılar gerçekleşen getirilerin beklenen getirinin iyi bir tahmincisi olmadığını savunmuş ve söz konusu durumun nedeni olarak bu yanlış kullanımı işaret etmişlerdir. Bu sebeple bu çalışmada BİST30 endeksine dâhil şirketlerin gerçekleşen getirileri ile gelecek getirileri arasındaki ilişki incelenmiştir. Gerçekleşen getiri olarak 1, 3 ve 5 yıllık aylık ortalama getiri, gelecek getiri olarak ise 1 ylllık gelecek aylık ortalama getiri kullanılmıştır. Gerçekleşen getiri dönemi kısaldıkça (1 ve 3 yıl için) literatürde ortalamaya dönüş olarak da bilinen (mean reversion) gerçekleşen ve gelecek getiri arasında negatif yönlü ilişki elde edilmiştir. Bu sonuca paralel bir sonuç olarak yapılan kategorik analizler sonucunda geçmiş getirileri düşük olan şirketlerin diğer gruplara göre gelecek getirileri daha yüksek, geçmiş getirileri yüksek olan şirketlerin gelecek getirisinin diğer gruplara göre daha düşük olduğu belirlenmiştir. Aradaki farklar istatistiksel açıdan anlamlı bulunmuştur. $\mathrm{Bu}$ bulgu 3 yıla kadar hesaplanan gerçekleşen getirilerin beklenen getirinin ölçüsü olarak kullanılamayacağını kesin olarak ortaya koymaktadır.

Gerçekleşen getiri dönemi olarak 5 yıl seçildiğinde ise pozitif yönlü ancak sıfıra oldukça yakın bir ilişki bulunmuştur. Nitekim lineer regresyon katsayısı 0,11 ve korelasyon katsayısı 0,04 olarak ölçülmüştür. Özetle 5 yıla kadar hesaplanan geçmiş getirilerle gelecek getiriler arasında pozitif yönlü bir ilişki bulunamamıştır.

Bu bulgular 5 yıla kadar hesaplanan gerçekleşen getirilerin beklenen getirinin iyi bir tahmincisi olmadığını göstermektedir. Hatta 3 yıla kadar dönemde bulunan negatif yönlü ilişki MPT'nin geleneksel portföy tekniklerine göre daha düşük performanslı portföyler üretmesinin bir nedeni olarak değerlendirilebilir. Dolayısıyla MPT ve diğer finansal teorilerinin ampirik testlerinde beklenen getirinin temsilcisi olarak gerçekleşen getiriden farklı olarak başka ölçütlerin kullanılması gerektiğini kesin olarak anlaşılmaktadır.

Bundan sonraki çalışmalarda gerçekleşen getiri dönemi için 5 yıldan daha uzun sürelerin alınarak ve farklı pay senetleri hatta pay senedinden farklı finansal varlıklar için sonuçlarının araştırılması literatüre katkı sağlayacaktır.

\section{KAYNAKLAR}

Bali, Turan G.- Demirtas, K. Ozgur- Levy, Haim (2008) "Nonlinear Mean Reversion in Stock Prices”, Journal of Banking \& Finance, Vol. 32(5): pp. 767-782.

Balvers, Ronald- Wu, Yangru- Gilliland, Erik (2000), "Mean Reversion across National Stock Markets and Parametric Contrarian Investment Strategies”, The Journal of Finance, Vol. 55(2): pp. 745-772.

Berg, Lennart (2005), “Portfolio Optimisation - Improved Risk-Adjusted Return?”, Department of Economics Uppsala University, Master Thesis. 
Brav, Alon- Lehavy, Reuven- Michaely, Roni (2004), “Using Expectations to Test Asset Pricing Models”, Working Paper, pp: 1-47.

Chaudhuri, Kausik- Wu, Yangru (2003), "Mean Reversion in Stock Prices: Evidence From Emerging Markets”, Managerial Finance, Vol. 29(10): pp. 22-37.

Demiguel, Victor (2009), "Optimal Versus Naive Diversification: How Inefficient is the 1/N Portfolio Strategy?”, The Review of Financial Studies, Vol. 22(5): pp. 1916-1953.

Deniz, Devran- Okuyan, H. Aydın (2018), “Geleneksel ve Modern Portföy Yönetiminin Ampirik Sonuçlarının Karşılaştırılması: Bist Uygulaması”, Mehmet Akif Ersoy Üniversitesi İktisadi ve İdari Bilimler Fakültesi Dergisi, Vol. 5(3): pp. 467-482.

Elton, Edwin J. (1999), “Expected Return, Realized Return, and Asset Pricing Tests”, The Journal of Finance, Vol. LIV(4): pp. 1199-1220.

Horimoto, Saburo- Tareq, Mohammad Ali (2013), “The Ex-Ante and Ex-Post Information of an Asset Return”, Seventh International Conference on Innovative Mobile and Internet Services in Ubiquitous Computing: pp. 743-748.

Karan, Baha (2011), Yatırım Analizi ve Portföy Yönetimi, 3. Baskı, Gazi Kitabevi, Ankara.

Kim, Myung Jig- Charles R. Nelson- Richard Startz (1991), "Mean Reversion in Stock Prices? A Reappraisal of the Empirical Evidence", The Review of Economic Studies, Vol. 58(3): pp. 515-528.

Mora, M. A.- Franco, J.B.- Preciado, L.B. (2010), “Optimal Portfolio Allocation for Latin American Stock Indices”, Cuad. Adm. Bogotá (Colombia) Enero-Junio De , Vol. 23(40): pp. 191-214.

Mukherji, Sandip (2011), “Are Stock Returns Still Mean-Reverting?”, Review of Financial Economics, Vol. 20: pp. 22-27.

Tang, Gordon Y. N. (2004), “How Efficient is Naive Portfolio Diversification?” An educational note, Omega, 32(2): pp. 155-160. 
